\title{
Emery-Dreifuss Muscular Dystrophy- Associated Mutant Forms of Lamin A Recruit the Stress Responsive Protein Ankrd2 into the Nucleus, Affecting the Cellular Response to Oxidative Stress
}

\author{
Silvia Angoria,b Cristina Capannia,b Georgine Faulknerc Camilla Bean ${ }^{c}$

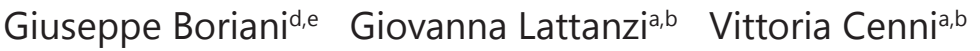 \\ anstitute of Molecular Genetics (IGM)-CNR, Unit of Bologna, Bologna, 'Laboratory of Musculoskeletal \\ Cell Biology, Rizzoli Orthopaedic Institute, Bologna, 'Department of Biology, University of Padua, \\ Padua, Institute of Cardiology, University of Bologna, S.Orsola-Malpighi University Hospital, Bologna, \\ eCardiology Division, Department of Diagnostics, Clinical and Public Health Medicine, University of \\ Modena and Reggio Emilia, Policlinico di Modena, Modena, Italy
}

\section{Key Words}

Ankrd2 (Ankyrin Repeat Domain 2) $\bullet$ EDMD2 (Emery-Dreifuss Muscular Dystrophy 2) • Lamin $\mathrm{A} / \mathrm{C} \cdot$ Prelamin $\mathrm{A} \cdot$ Human muscle cells $\bullet$ Oxidative stress

\begin{abstract}
Background: Ankrd2 is a stress responsive protein mainly expressed in muscle cells. Upon the application of oxidative stress, Ankrd2 translocates into the nucleus where it regulates the activity of genes involved in cellular response to stress. Emery-Dreifuss Muscular Dystrophy 2 (EDMD2) is a muscular disorder caused by mutations of the gene encoding lamin $\mathrm{A}$, LMNA. As well as many phenotypic abnormalities, EDMD2 muscle cells also feature a permanent basal stress state, the underlying molecular mechanisms of which are currently unclear. Methods: Experiments were performed in EDMD2-lamin A overexpressing cell lines and EDMD2-affected human myotubes. Oxidative stress was produced by $\mathrm{H}_{2} \mathrm{O}_{2}$ treatment. Co-immunoprecipitation, cellular subfractionation and immunofluorescence analysis were used to validate the relation between Ankrd2 and forms of lamin A; cellular sensibility to stress was monitored by the analysis of Reactive Oxygen Species (ROS) release and cell viability. Results: Our data demonstrate that oxidative stress induces the formation of a complex between Ankrd 2 and lamin A. However, EDMD2-lamin A mutants were able to bind and mislocalize Ankrd2 in the nucleus even under basal conditions. Nonetheless, cells co-expressing Ankrd2 and EDMD2lamin A mutants were more sensitive to oxidative stress than the Ankrd2-wild type lamin A counterpart. Conclusions: For the first time, we present evidence that in muscle fibers from patients affected by EDMD2, Ankrd2 has an unusual nuclear localization. By introducing a plausible mechanism ruling this accumulation, our data hint at a novel function of Ankrd2 in the pathogenesis of EDMD2-affected cells.




\section{Cellular Physiology Cell Physiol Biochem 2017;42:169-184 and Biochemistry Publisned online: 1vay 18, $2017 \quad \begin{aligned} & \text { D 2017 The Authorst } \\ & \text { www.karger.com/cpb }\end{aligned}$}

Angori et al.: Ankrd2 is a Novel Interactor of Lamin A and Prelamin A

\section{Introduction}

Ankrd2, Ankyrin repeat protein 2, is a mechanosensing protein, belonging to the MARP (Muscle Ankyrin Repeat Protein) family and is mainly expressed in skeletal muscle [1-3]. Ankrd2 gene expression is positively modulated by MyoD, a muscle-specific transcription factor, that ensures Ankrd2 expression to be low in cycling myoblasts, however its expression increases upon muscle differentiation [4]. In cycling myoblasts, Ankrd2 is sharply nuclear, whereas in forming myotubes it has a typical cytonuclear localization [5]. The fine tuning of its subcellular localization and expression is due to the different roles covered by Ankrd2 during myogenesis: an earlier nuclear function, and a late sarcomeric one [5]. In the nucleus, Ankrd2 binds to multiple transcription factors, such as YB1, ID3, PAX6, LHX2 and MECP2 [6-8], as well as p53, and PML [6]. In the cytoplasm, Ankrd2 interacts with proteins involved in cell signaling, such as Akt2 [9], and PLC $\gamma$ [7], but also with sarcomeric proteins, such as telethonin [6], titin [10] and ZASP6 [11].

Ankrd2 shuttling in the nucleus may also be regulated by several types of stress. Oxidative stress [9], as well as chronic immobilization [12], exercise [13], or mechanical forces [10] promote the overexpression of Ankrd2 and its concomitant nuclear translocation. In these conditions, by down-regulating MyoD, Myogenin and their target Myh3 [5], nuclear Ankrd2 transiently interrupts the differentiation of muscle fibers, allowing the cells to cope with stress. The tight relation between its role of stress sensor and coordinator of differentiation, has therefore enabled us to define Ankrd2 as a "stress responsive protein".

Lamin A, its precursor prelamin A, and lamin C are splicing products encoded by the LMNA gene [14]. In the nucleus, along with B-type lamins, they give rise to the nuclear lamina, an elastic network linked to the inner nuclear membrane. By interacting with structural and enzymatic molecules, lamin A/C are able to comply with several functions, including nuclear and DNA protection against mechanical stress, shuttling of proteins from the cytoplasm to the nucleus, and epigenetic modification of chromatin, affecting gene expression during cell cycle and/or differentiation [15-18]. In muscle cells, by interacting with the LINC complex proteins, lamin $A / C$ is also connected to sarcomeric proteins $[19,20]$.

As lamin $\mathrm{A} / \mathrm{C}$ is so deeply involved in many pleiotropic functions, mutations in the LMNA gene often result in their alteration, with deleterious consequences for cells and tissue physiology. The disorders due to LMNA mutations fall into the family of "laminopathies", which can be tissue-specific, targeting striated muscle tissue, adipose or nerve tissue, or systemic, as progeroid syndromes [14].

LMNA-related muscle laminopathies cover a wide number of pathologies, the most known of which is Emery-Dreifuss Muscular Dystrophy 2 (EDMD2) [21, 22]. EDMD2 is characterized by early contractures, progressive muscle atrophy and weakness, with cardiac defects that cause conduction system disorders and dilated cardiomyopathy and may lead to sudden death; in particular, several pathogenetic variants of $L M N A$, mapping on diverse sites of the gene, have been identified for being causative of EDMD2 [22-24]. Scientists support the theory according to which in affected fibers, mutations of LMNA result in a reduced ability of the nuclear lamina to maintain the mechanical integrity of myofibers and the organization of the sarcomere, following contractile stimulation [25]. Recent findings also suggest an impairment of signaling mechanisms affecting the regulation of musclespecific gene expression [21]. Nevertheless, the severity of the disease is often associated to altered levels of reactive oxygen species and a higher susceptibility to oxidative stress [26]. Multiple evidence points to mutations on lamin $\mathrm{A} / \mathrm{C}$, and on the resulting dysfunctional lamina, to be indeed responsible for an altered redox homeostasis [27]. Beside lamin A/C, also prelamin A, the precursor of lamin A longer for 15 amino acids, plays a fundamental role in muscle cells. We have in the past demonstrated that in normal conditions, prelamin $\mathrm{A}$ is accumulated during muscle cell differentiation [28]. Moreover, by interacting with LINC complex, farnesylated-prelamin A, one intermediate of lamin A processing [29], contributes to nuclear positioning in human myofibers, providing a novel role for this precursor in the 


\section{Cellular Physiology Cell Physiol Biochem 2017;42:169-184

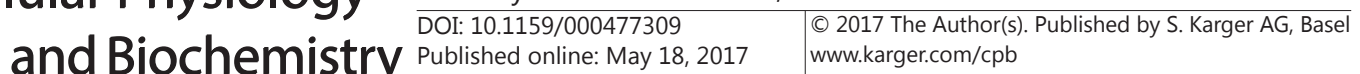

Angori et al.: Ankrd2 is a Novel Interactor of Lamin A and Prelamin A

pathogenic mechanisms of dystrophic muscle cells accumulating a mutated form of prelamin A [30].

In this study, we present evidence of the formation of a complex made of Ankrd2, mature lamin A and farnesylated prelamin A, suggesting an involvement of lamin A and prelamin A in Ankrd2 nuclear translocation observed during the arrival of certain stimuli, such as myogenic stimulation or stress conditions. In an attempt to assess whether mutations of LMNA causative of EDMD2 might affect Ankrd2 binding to lamin A, we unexpectedly found that pathological EDMD2-lamin A mutations positively affect this binding and promote Ankrd2 mislocalization in the nucleus, even under basal conditions. Intriguingly, our findings show that the pathological recruitment of Ankrd2 in the nucleus of EDMD2 fibers may play a relevant role in the pathogenesis of this condition by increasing cellular sensibility to oxidative stress.

\section{Materials and Methods}

Cultures, transfection and treatments

Human muscle cultures were obtained as previously described [31] from consenting patients undergoing cardiac pacemaker, or defibrillator implant or replacement. The EDMD2 biopsy was from an affected donor in which a novel LMNA mutation (c.1517A $>$ C) was diagnosed (Cenni et al, manuscript in preparation). All the local and EU ethical issues were respected.

Human embryonic kidney (HEK) 293T cells and C2C12 myoblasts were cultured in DMEM-High Glucose (Life-Technologies, Netherlands) supplemented with 10\% of heat-inactivated Fetal Calf Serum (EuroClone, Leeds, U.K.). C2C12 were induced to differentiate in DMEM-HG plus 2\% Horse Serum (Euroclone). HEK 293T were transfected with Fugene6 (Promega Madison, USA), and C2C12 with Lipofectamine-3000 (Invitrogen, Waltham, USA).

Oxidative stress was induced by $\mathrm{H}_{2} \mathrm{O}_{2}$ (Sigma-Aldrich, St. Louise USA) at a final concentration of $450 \mu \mathrm{M}$ for HEK 293T and C2C12 cells for the indicated times. Lower $\mathrm{H}_{2} \mathrm{O}_{2}$ concentration (f.c. $100 \mu \mathrm{M}$ ) was used for primary muscle cultures, to exclude sublethal effects.

\section{Plasmids}

For Ankrd2: Flag tagged human Ankrd2 was previously described in [9]. GFP-tagged human Ankrd2 cDNA, encoding for the S-Ankrd2 isoform of 333 aminoacids, described by Jasnic-Savovic et al. [3], was cloned into the pCDNA 3.1 eukaryotic expression vector (Invitrogen). For Flag-lamin A: Flag-lamin A WT [32], Flag-lamin A WT cDNA was used as a template to generate mutants C661M, L647R, R401C, R527P and H506P by means of QuikChange strategy (Agilent Technologies, Santa Clara, USA). LA L647R was used to create double mutants L647R/R401C, L647R/R527P and L647R/H506P. Mutagenesis was verified by DNA sequencing (BMR, Padua, Italy). Mutagenesis primers (Invitrogen) used are shown in Suppl. Table S1 (for all online suppl. material, see www.karger.com/doi/10.1159/000477309).

Preparation of protein extracts and co-immunoprecipitation

Total lysates were prepared in AT lysis buffer (20mM Tris-HCl 7.0, 1\% NP-40, 150mM NaCl, 10\% glycerol, $10 \mathrm{mM}$ EDTA, 20mM NAF, $5 \mathrm{mM} \mathrm{Na}_{4} \mathrm{P}_{2} \mathrm{O}_{7}, 1 \mathrm{mM} \mathrm{Na}_{3} \mathrm{VO}_{4}, 1 \mathrm{mM}$ PMSF and protease inhibitors (ThermoScientific, Waltham, USA) at $4^{\circ} \mathrm{C}$.

For nuclear extraction: transfected-HEK 293T were trypsinized and resuspended in hypotonic buffer $\left(10 \mathrm{mM}\right.$ Tris- $\left.\mathrm{HCl} \mathrm{pH} 7.8,5 \mathrm{mM} \mathrm{MgCl}_{2}\right)$. Then, $0.3 \%$ Triton was added. Cells were then sheared through a $22-\mathrm{G}$ needle. Nuclei were recovered by centrifugation, lysed in AT lysis buffer and cleared by centrifugation. The purity of nuclei was analyzed by immunoblot detection of $\beta$-tubulin.

For co-immunoprecipitation experiments, cells were lysed in CC buffer (50mM Tris- $\mathrm{HCl}$ 8.0, 150mM $\mathrm{NaCl}, 1 \% \mathrm{NP} 40,0.1 \%$ SDS and protease inhibitors). Lysates (1-2mg) were incubated with $2 \mu \mathrm{g}$ of antibody at $4^{\circ} \mathrm{C}$. Immunocomplexes were pelleted by protein A/G-agarose beads (Santa-Cruz Biotech, Santa Cruz, USA). Pellets were washed with CC buffer, and finally boiled in Laemmli buffer for Western blot analysis. 


\section{Cellular Physiology Cell Physiol Biochem 2017;42:169-184 \begin{tabular}{l|l} 
and Biochemistry Publisned onIIne: IVay 18, 2017 & $\begin{array}{l}\text { () 2017 The Author(s). Published by S. Karger AG, Basel } \\
\text { www.karger.com/cpb }\end{array}$
\end{tabular}}

Angori et al.: Ankrd2 is a Novel Interactor of Lamin A and Prelamin A

\section{Immunochemical analysis}

$50 \mu \mathrm{g}$ of lysates were resolved on SDS-PAGE. Proteins were blotted onto nitrocellulose (BioRad). For the detection of human or mouse Ankdr2, the following antibodies were used: polyclonal anti Ankrd2, (PtgLab Chicago, USA) and monoclonal anti-Ankrd2, clone YAS11 (LS-Bio Seattle, USA). As stated by the companies, these two antibodies have been raised against epitopes shared by the S- and the M- Ankrd2 isoforms. Other antibodies were: anti -Akt SC-1619, -Akt SC-1618, -Lamin A/C SC-6215, -Lamin A SC-6214, -GFP, -PARP-1 SC-7150, -Bcl-2 SC-7382, caspase-3 SC-7148, BAX sc-7480 (all Santa Cruz, USA).

\section{Immunofluorescence microscopy}

Cells were grown on coverslips and fixed in methanol at RT for 7-15'. Cells were blocked and incubated with primary antibodies overnight at $4^{\circ} \mathrm{C}$ and with fluorescence-labeled secondary antibodies (DAKO, Denmark, or Santa Cruz, USA). Coverslips were washed and mounted with an antifade/DAPI reagent (Sigma-Aldrich, USA). Images were captured and analyzed with a Nikon-E600 fluorescence microscope, by the NIS-Elements AR-software.

\section{Measurement of intracellular ROS level}

HEK 293T were transfected according to the experimental conditions. Due to fluorescence interference, whenever required, a vector encoding Flag-tagged Ankrd2 was used to overexpress Ankrd2 in these experiments. The day before the experiment, cells were splitted and $5 \times 10^{4}$ cells were seeded in triplicate in a 96-wells culture plate. The next day, cells were washed and incubated with 15 $\mathrm{M}$ DCFDA (dichlorofluorescin-diacetate, Sigma- Aldrich) for $30^{\prime}$ at $37^{\circ} \mathrm{C}$. Cells were stimulated with $\mathrm{H}_{2} \mathrm{O}_{2}$ or left untreated. Fluorescence intensity of oxidized DCFH (dichlorofluorescein) was detected with a fluorescent plate reader (Infinite M200-6110, Tecan, Switzerland). Human muscle cells were seeded in triplicate in a 96-wells culture plate, differentiated for three weeks and then processed as already described.

All the images shown are representative of at least three independent experiments carried out under the same conditions. Images from immunochemical and immunofluorescence studies were processed using Adobe-Photoshop CS 8.0 (Adobe-Systems). Densitometric and statistical analysis were performed by ImageJ and GraphPad Prism5 software.

\section{Results}

Ankrd2 interacts with lamin $A$ and prelamin $A$, and is mislocated from the cytoplasm to the nucleus by farnesylated prelamin $A$

Ankrd2 and LMNA products have several features in common: they are upregulated during muscle differentiation, have a nuclear localization (which is constitutive for lamin $\mathrm{A} / \mathrm{C}$ and regulated for Ankrd2), and interact with chromatin and transcription factors, such as p53. Thus, we wondered whether these proteins might interact with each other. HEK 293T cells, which do not endogenously express Ankrd2, and have negligible amounts of endogenous lamin A or C [33], were co-transfected with vectors encoding GFP-Ankrd2 and Flag-tagged constructs encoding wild-type lamin A (LA WT) or some unprocessable intermediates of lamin A maturation, such as non-farnesylable (LA C661M), and carboxymethylatedfarnesylated prelamin A (LA L647R). A scheme of lamin A maturation steps and mutants used in this work is depicted in Fig. S1, see supplementary material.

Cell lysates of Flag-LA constructs transfected in HEK293T cells were immunoprecipitated and analyzed for Ankrd2. Results shown in Fig. 1A demonstrate that Ankrd2 is able to complex with all the forms of lamin A tested. However, more Ankrd2 was found in prelamin A immunoprecipitates, in particular in the LA L647R one.

To confirm biochemical evidence and evaluate whether Ankrd2 localization is affected by prelamin A accumulation, HEK 293T cells were transfected with GFP-Ankrd2 alone or in combination with Flag-LA constructs, and subjected to cellular fractionation. Results shown in Fig. 1B, revealed that the simultaneous co-expression with LA C661M and even more so with LA L647R increased Ankrd2 accumulation in the nuclear fraction, compared to what was observed when it was co-expressed with LA WT (respectively of $\sim 45 \%$ and 


\section{Cellular Physiology Cell Physiol Biochem 2017;42:169-184

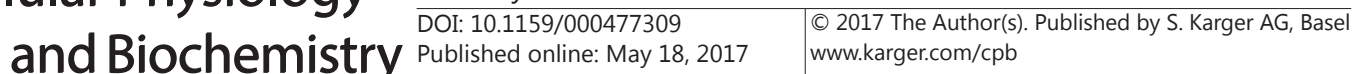

Angori et al.: Ankrd2 is a Novel Interactor of Lamin A and Prelamin A

Fig. 1. Lamin A and farnesylated prelamin A interact with Ankrd2, but only farnesylated prelamin A shifts Ankrd2 into the nucleus. HEK 293T cells were co-transfected with GFP-Ankrd2 and the indicated Flag (Fl)-lamin A constructs, encoding wild type mature lamin A (LA WT), non-farnesylable (LA C661M) and carboxymethylated-farnesylated prelamin A (LA L647R), and with empty vector (EV) as control, After 24 hours, cells were processed for: A) Co-immunoprecipitation assay: lamin $\mathrm{A}$ and prelamin A forms were immunoprecipitated from total cell lysates (T.L.) by an anti-Flag antibody. Pellets were resolved on a $10 \%$ SDS-PAGE and subjected to immunoblot analysis. Representative western blots are shown. Bars were obtained by normalizing GFP-Ankrd2 to Flag densitometric values from six independent coimmunoprecipitation assays. Plots are mean \pm SD $(n=6) .{ }^{*} p<0.05$ vs. Ankrd2 amount co-immunoprecipitated with LA WT. Western blots directed against GFPAnkrd2 (MW: 67kDa), and densitometric analysis revealed that Ankrd2 preferentially binds to farnesylated prelamin A. Note that the unprocessable prelamin A species, i.e. LA C661M and LA L647R are about 15 aa longer than LA WT, and thus run slower. B) Nuclear extraction: Nuclear extracts isolated from transfected cells were lysed, resolved on SDS-PAGE and immunoblotted with an anti-GFP antibody. As assessed by corresponding total lysates, GFP-Ankrd2 was equally transfected in each sample. Purity of isolated nuclei was checked by $\beta$-tubulin. HDAC2 was used as an equal loading control of nuclear lysates. Of note, when expressed alone, in HEK 293T cells (which express negligible levels of lamin A/C) GFP-Ankrd2 is accumulated in the nucleus. Representative blots from five independent experiments are shown. Bars were obtained by normalizing densitometric values of GFP-Ankrd2 in the nucleus to those in total lysates from the corresponding sample. Plots are mean \pm SD $(n=5) .{ }^{*} p<0.05$ vs. GFP-Ankrd2 amount obtained from fraction of Fl-LA WT-transfected cells.C) Immunofluorescence analysis: In co-transfected HEK 293T cells, GFP-Ankrd2 (green) localization was evaluated in combination with the indicated Flag (Fl)-lamin A forms stained in red by an anti Cy3-conjugated secondary antibody against the anti-Flag. Nuclei were counterstained with DAPI (blue). Bar $10 \mu \mathrm{m}$. More significant nuclei (indicated by arrowheads) were magnified to gain more insight into GFP-Ankrd2 nuclear localization. As previously reported, Fl-LA L647R accumulation leads to the formation of nuclear lamina thickening, and is predominantly localized in the nucleoplasm, as well as the nuclear rim. Fl-LA C661 M unprocessable prelamin A predominantly accumulated at intranuclear aggregates while a minor percentage of cells, showed a nuclear lamina distribution. The overexpression of Fl-LA L647R mutant led to the accumulation of GFP-Ankrd 2 in the nuclei of $60 \pm 5 \%$ of co-transfected cells. It

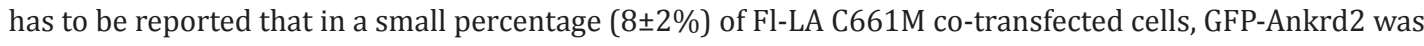
interestingly localized at the nuclear rim.

$\sim 54 \%$ more, Fig. 1B). Of note, in HEK 293T cells expressing GFP-Ankrd2 alone, the amount of nuclear Ankrd2 was similar to that observed with the prelamin A form, maybe because of the absence of a normal nuclear lamina typical of these cells [33]. Increasing the detergent concentration in the extraction buffer (up to 1\% Triton X-100), did not affect LA L647R- 


\section{Cellular Physiology Cell Physiol Biochem 2017;42:169-184

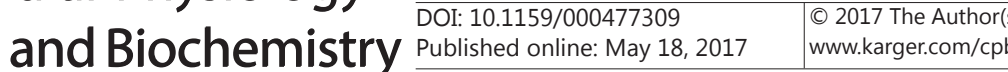 \\ Angori et al.: Ankrd2 is a Novel Interactor of Lamin A and Prelamin A}

induced Ankrd2 accumulation in the nuclear fraction, indicating that Ankrd2 was not bound to the outer nuclear membrane (not shown). Further fractionation revealed that Ankrd2 was accumulated in the insoluble nuclear fraction (In), containing the nuclear matrix and chromatin, after LA L647R, but not WT, expression (see supplementary material, Fig. S2).

Ankrd2 localization was next explored by immunofluorescent analysis of co-transfected cells. Confirming previous evidence, when expressed with LA WT, Ankrd2 was mainly cytoplasmic and weakly nuclear. However, co-expression with the LA L647R mutant led Ankrd2 to be recruited to the nucleus in $60 \pm 5 \%$ of the transfected cells. Limited localization changes compared to control (Ankrd2-LA WT co-expressing cells) were detectable by coexpressing LA C661M (read legend of Fig. 1C).

\section{Ankrd2 interacts strongly with EDMD2 mutated forms of farnesylated prelamin A}

EDMD2 is a genetic disorder due to mutations of the LMNA gene encoding lamin A, impairing the development and functions of striated muscles. To get more insight into the role of the interaction between Ankrd2 and mutated lamin A in the pathophysiology of this disease, some forms of EDMD2-mutated lamin A were produced from LA WT, and their affinity of binding with Ankrd2 assayed. In particular, LMNA mutations considered were: c.1201C >T/p.R401C [34], c.1580G>C/p.R527P [23] and the novel mutation identified by us, that is c.1517A $>$ C leading to the p.H506P mutation, responsible for an EDMD2 associated to cardiac conduction defects (Cenni et al. manuscript in preparation).

HEK 293T were co-transfected with vectors encoding GFP-Ankrd 2 and the various forms of EDMD2-mutated lamin A. After 24 hours, the Flag constructs were immunoprecipitated from total lysates and then analyzed for Ankrd2. Results demonstrated that compared to LA $\mathrm{WT}$, the presence of the EDMD2 mutations positively modulated the binding between lamin A and Ankd2 (Fig. 2A and 2B).

We next tested whether the introduction of the same mutations in the unprocessable prelamin A mutant could affect the interaction between Ankrd2 and prelamin A already reported (Fig. 1A). To this aim, the double mutants L647R/R401C, L647R/H506P and L647R/R527P (hereafter indicated as $\mathrm{dm}$ R401C, dm H506P and dm R527P), were created and co-expressed with GFP-Ankrd2. Overexpressing cells were lysed and prelamin A forms immunoprecipitated.Results demonstrated that double lamin A mutants coimmunoprecipitated an amount of Ankrd2 higher than that observed with LA WT or single EDMD2-lamin A mutants (Fig. 2A and 2B), or with LA L647R (see supplementary material, Fig. S3).

To evaluate whether lamin A mutants were also able to recruit Ankrd2 to the nucleus, Ankrd2 localization was then verified by immunofluorescence analysis. Results proved that all the EDMD mutated-lamin A forms tested were able to induce a portion of total Ankrd2 to be confined in the nucleus (Fig. 2C).

To verify that the interaction between Ankrd2 with wild-type and mutated lamin A forms also occurs in a muscle model, C2C12 mouse muscle cells were cultured on coverslips, transfected with vectors encoding the various forms of Flag-tagged lamin A forms and differentiated for two days. Cells were blocked and slides incubated with anti-Flag antibody to stain transfected cells, and with anti-Ankrd2 antibody to stain endogenous Ankrd2. As shown in Fig. 2D, in mock and LA WT-transfected cells, Ankrd2 stained both the cytoplasm and the nuclei of nascent myotubes. However, confirming previous data, in cells overexpressing EDMD2-lamin A, Ankrd2 localization became more nuclear (Fig. 2D).

In C2C12 myotubes, $\mathrm{H} 2 \mathrm{O} 2$ increases the binding between endogenous Ankrd2 and lamin A

As previously reported, oxidative stress induces a portion of Ankrd2 to translocate from the cytoplasm to the nucleus, affecting the activity of its effectors [9]. In an attempt to evaluate whether oxidative stress could modulate the binding between Ankrd2 and lamin A during Ankrd2 nuclear crossing, $\mathrm{C} 2 \mathrm{C} 12$ cultured myotubes were stressed by $\mathrm{H}_{2} \mathrm{O}_{2}$ stimulation (f.c. $450 \mu \mathrm{M}$ ) up to 5 hours, lysed and endogenous lamin A/C immunoprecipitated from total lysates. Fig. $3 \mathrm{~A}$ shows that $\mathrm{H}_{2} \mathrm{O}_{2}$ stimulation positively promoted the interaction between 


\section{Cellular Physiology Cell Physiol Biochem 2017;42:169-184 \begin{tabular}{l|l} 
and Biochemistry Published onlne: May 18, 2017 & $\begin{array}{l}\text { ( ) 2017 The Author(s). Published by S. Karger AG, Basel } \\
\text { www.karger.com/cpb }\end{array}$ \\
\hline
\end{tabular}}

Fig. 2. Ankrd2 tightly interacts with EDMD2mutated forms of lamin A and prelamin A. A) Co-immunoprecipitation analysis of HEK 293T cells transfected with GFP-Ankrd2 and Flag-lamin A constructs encoding wild type lamin A (LA WT), EDMD2 forms of lamin A, that is LA R401C, LA H506P and LA R527P, and EDMD2-forms of prelamin A, that is double mutants L647R/ R401C, L647R/H506P and L647R/R527P (dm R401C, dm H506P and $\mathrm{dm}$ R527P). After 18-24 hours from transfection, cells were lysed and lamin A species immunoprecipitated from total lysates (T.L.) by anti-Flag antibody. GFP-Ankrd2 amount was then quantified in the Flag-

ing GFP-Ankrd2 to Flag densitometric values from three independent immunoprecipitation assays. Plots are mean \pm SD $(n=3) .{ }^{*} p<0.05$ vs. Ankrd2 amount obtained from Fl-LA WT-transfected cells. C) Immunofluorescence analysis: GFP-Ankrd2 localization was evaluated in cells overexpressing Flag (Fl-) tagged EDMD2 mutant forms of lamin A (LA R401C, LA H506P and LA R527P) and prelamin A (dm R401C, dm H506P and dm R527P). Mutated lamin A overexpressing cells were detected by anti-Flag staining (red), bar $10 \mu \mathrm{m}$. Arrowheads-marked nuclei were magnified to detect differences in GFP-Ankrd2 localization. To avoid artefactual data due to accumulation of transfected proteins, the same experiments were performed with serial dilutions of expression vectors (range of transfecting DNA used was from 0.2 to $1.5 \mu \mathrm{g} /$ well for a 6-well plate). D) Subconfluent C2C12 cells grown on coverslips were transfected with vectors encoding Fl-tagged LA R401C, LA H506P and LA R527P and induced to differentiate in differentiation medium. After two days of differentiation, cells were harvested and treated for immunofluorescence or Western blot analysis. For immunofluorescence: cells were fixed, blocked saturated and analyzed with antibodies directed against endogenous Ankrd2 (green) and Flag tagged EDMD2-lamin A mutants (stained with anti-Flag/cy3-conjugated antibody from Sigma). Bar $10 \mu \mathrm{m}$. Similar results were obtained by serial dilution of transfected cDNA vectors (not shown). Western blot analysis of the same samples confirmed levels of endogenous Ankrd2 and exogenous lamins. Representative blots from three independent experiments are shown.

Ankrd2 and lamin A/C. It should be noted that Ankrd2 did co-immunoprecipitate with lamin $\mathrm{A} / \mathrm{C}$ also in untreated conditions, confirming its nuclear functions during myogenesis. Interestingly, after three hours of treatment, the amount of Ankrd2 bound to lamin $\mathrm{A} / \mathrm{C}$ started decreasing.

Ankrd2 and lamin A/C interplay was then investigated by immunofluorescence analysis. C2C12 myotubes were grown on coverslips and cultured and treated as before. At the end of 


\section{Cellular Physiology Cell Physiol Biochem 2017;42:169-184 \begin{tabular}{c|c|c|} 
DOI: 10.1159/000477309 & $\begin{array}{l}\text { O 2017 The Author(s). Published by S. Karger AG, Basel } \\
\text { www.karger.com/cpb }\end{array}$ \\
\hline and Biochemistry
\end{tabular}}

Fig. 3. $\mathrm{H}_{2} \mathrm{O}_{2}$ stimulation positively modulates the binding between wild-type forms of mature lamin A and prelamin A but not that with overexpressed EDMD2 mutated forms of lamin A. To evaluate whether $\mathrm{H}_{2} \mathrm{O}_{2}$ modulates the binding of endogenous Ankrd2 and lamin $\mathrm{A} / \mathrm{C}$ also in a muscle model: A) C2C12 cells were seeded in p100 plates with coverlips inside, differentiated for 2 days and exposed to $450 \mu \mathrm{M}$ $\mathrm{H}_{2} \mathrm{O}_{2}$ for the indicated times, or left untreated. At the end of every treatment, cells were lysed and endogenous lamin $\mathrm{A} / \mathrm{C}$ immunoprecipitated by an anti-lamin A/C antibody (SC-6215, directed against lamin $\mathrm{A} / \mathrm{C}$ and prelamin A) from total lysates (T.L.). As a control, anti IgG sera was incubated with same amount of untreated total lysate. $\mathrm{H}_{2} \mathrm{O}_{2}$ stimula-
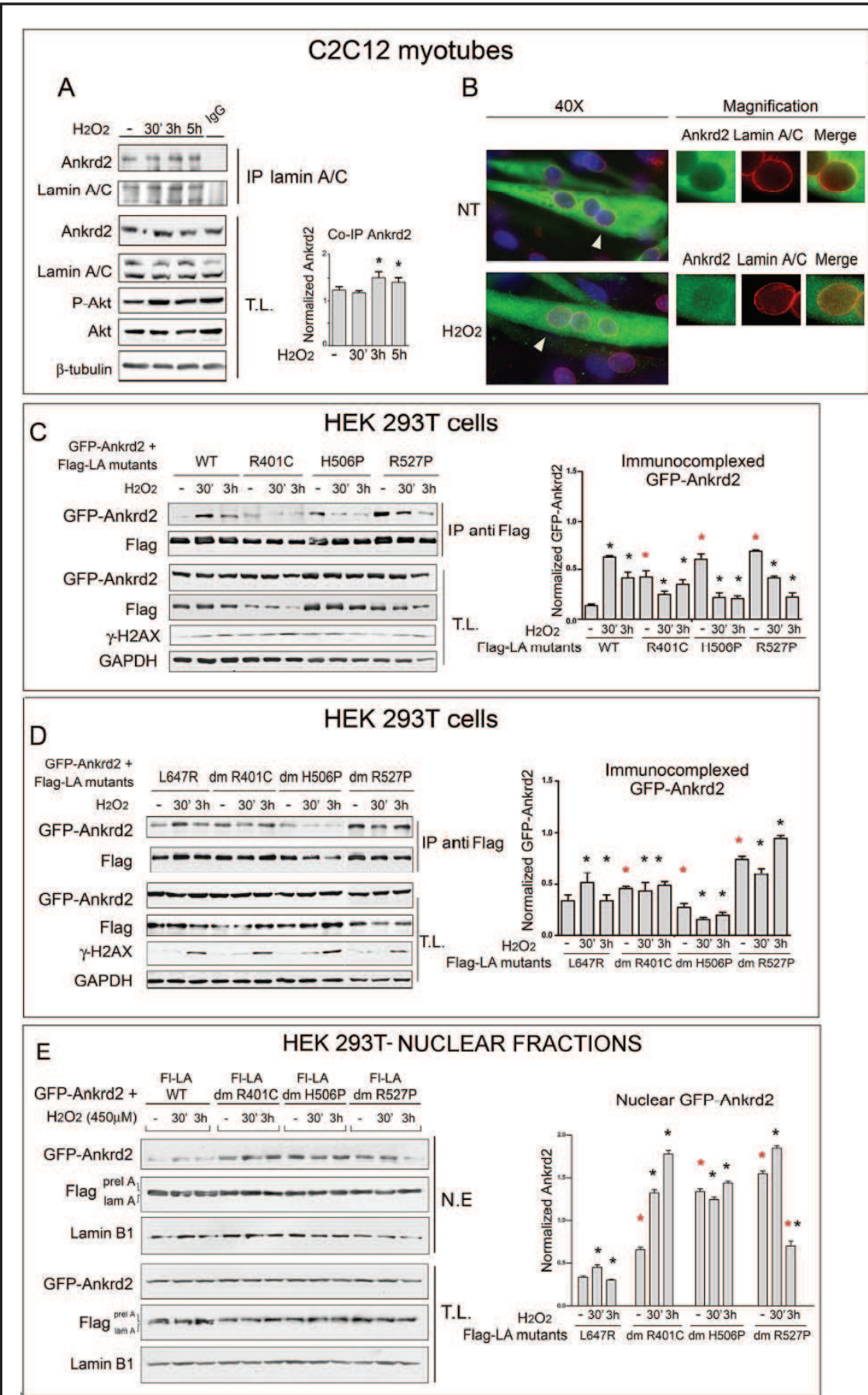

tion efficacy was monitored by detection of phosphorylation at Ser-473 of Akt (P-Akt, Cell Signaling). Immunocomplexes were immunoblotted with an anti Ankrd2 antibody (polyclonal). Representative western blots are shown. Bar graph was obtained by normalizing immunoprecipitated Ankrd2 to lamin A/C densitometric values from three independent experiments. Plots are mean $\pm \mathrm{SD}(n=3) .{ }^{*} p \leq 0.05$ vs. Ankrd2 amount obtained from untreated complexes. $\mathrm{H}_{2} \mathrm{O}_{2}$ stimulation promoted the interaction between Ankrd2 and lamin A/C by $\sim 15 \%$ more compared to untreated conditions. B) To confirm nuclear translocation of Ankrd2 upon stress, coverslips from A) treated for 3 hours with $\mathrm{H}_{2} \mathrm{O}_{2}$ and untreated, were processed for immunofluorescence analysis and incubated with antibodies directed against endogenous Ankrd2 (green) and endogenous lamin A/C (red). Partial nuclear co-localization of Ankrd2 and lamin A increases upon stimulation, as suggested by the yellow signal. To check whether $\mathrm{H}_{2} \mathrm{O}_{2}$ affects the extent of the interaction between Ankrd2 


\section{Cellular Physiology Cell Physiol Biochem 2017;42:169-184 and Biochemistry Publisned online: 1vay 18, $2017 \quad \begin{aligned} & \text { D 2017 The Authors. } \\ & \text { www.karger.com/cpb }\end{aligned}$}

Angori et al.: Ankrd2 is a Novel Interactor of Lamin A and Prelamin A

and mutated forms of lamin A or prelamin A, HEK 293T cells were transfected with GFP-Ankrd2 and the indicated forms of Flag (Fl-) tagged lamin A (C) and prelamin A (D) constructs. After 48 hours, cells were stimulated with $450 \mu \mathrm{M} \mathrm{H}_{2} \mathrm{O}_{2}$ for the indicated times, and Flag-tagged proteins were immunoprecipitated by anti-Flag antibody. Immunocomplexes were resolved by a 8\% SDS-PAGE and GFP-Ankrd2 amount was quantified. $\mathrm{H}_{2} \mathrm{O}_{2}$ efficacy was monitored by the increase of phosphorylated H2AX at Ser-139 (anti $\gamma \mathrm{H} 2 \mathrm{AX}$, from Abcam). Representative blots are shown. Bar graphs were obtained by normalizing GFP-Ankrd2 to Flag densitometric values from three independent experiments. Plots are mean $\pm \operatorname{SD}(n=3) .{ }^{*} p<0.05$ with black asterisks vs. GFP-Ankrd2 amount obtained from precipitates with the same lamin A construct untreated samples. ${ }^{*} p<0.05$ with red asterisks vs. GFP-Ankrd2 amount obtained from precipitates with LA WT for C) and with LA L647R for D). E) To evaluate whether GFP-Ankrd2 accumulation into the nuclear fraction following $\mathrm{H}_{2} \mathrm{O}_{2}$ stimulation might be affected by mutated lamin A overexpression, HEK 293T cells were transfected with GFP-Ankrd2 and the reported Flag tagged double mutants forms of lamin A (dm R401C, dm H506P and dm R527P) and with Fl-lamin A WT (WT) as the control. After $24 \mathrm{~h}$ of transfection, cells were subjected to nuclear extraction. Total lysates and nuclear extracts were resolved by 10\% SDS-PAGE and blotted with the reported anti-Ankrd2 antibody. Lamin B1 was used as equal loading control of total and nuclear lysates. Purity of the nuclear fraction was validated by the absence of $\beta$-tubulin (not shown). Representative blots are shown. Bars graphs were obtained from densitometric analysis of nuclear GFP-Ankrd2 of three independent experiments, values were normalized to nuclear lamin B1 and indicate means \pm S.D $(n=$ 3). ${ }^{*} p<0.05$ vs. GFP-Ankrd2 nuclear amount obtained from the same lamin A construct-transfected control (untreated) samples. ${ }^{*} p<0.05$ with red asterisks vs. GFP-Ankrd2 nuclear amount obtained from LA WT transfected and untreated cells.

every treatment, cells were fixed and stained for endogenous Ankrd2 and lamin A/C. Fig. 3B shows that in untreated controls (NT), Ankrd2 was mainly cytosolic and faintly nuclear in $70 \%$ of the myotubes. In this context, it was also evident that the signals of Ankrd 2 and lamin $\mathrm{A} / \mathrm{C}$ merged at the nuclear rim (see the yellow staining at the nuclear rim Fig. 3B, NT). In the remaining percentage, consistent with the active role of Ankrd2 in coordinating muscle differentiation from the nuclei [4], Ankrd2 was also localized inside the nuclei (not shown).

Myotube exposure to oxidative stress induced a partial translocation of Ankrd2 to the nucleus, clearly detectable after three (Fig. $3 \mathrm{~B}, \mathrm{H}_{2} \mathrm{O}_{2}$ ) or five hours (not shown) of stimulation. Under these conditions, the merged signal from Ankrd2 and lamin $\mathrm{A} / \mathrm{C}$ staining at the nucleus became clearer (Fig. $3 \mathrm{~B}, \mathrm{H}_{2} \mathrm{O}_{2}$ ).

Taken together, co-immunoprecipitation (Fig. 3A) and immunofluorescence (Fig. 3B) results suggest that the increased binding between Ankrd2 and lamin A observed upon the application of oxidative stress, probably contributes to the increase in nuclear localization of Ankrd2.

We next tested if oxidative stress might modulate also the interaction between Ankrd2 and the EDMD2 mutated forms of lamin A. HEK 293T were transfected with GFP-Ankrd2 in combination with Flag-tagged constructs encoding LA WT, LA L647R, and single or double EDMD2-lamin A mutants. Cells were subjected to stress by $\mathrm{H}_{2} \mathrm{O}_{2}$ stimulation for a short (30 minutes) or a longer (3 hours) exposure, and Flag immunoprecipitated from total lysates. Results shown in Fig. 3C and 3D revealed that short exposure to $\mathrm{H}_{2} \mathrm{O}_{2}$ stimulation (30 min) upregulated Ankrd2 binding to LA WT or farnesylated prelamin A, whereas it reduced Ankrd2 binding to mutated forms of lamin A (Fig. 3C and 3D). Interestingly, longer $\mathrm{H}_{2} \mathrm{O}_{2}$ exposure decreased Ankrd2 binding to all the WT and mutant lamin A forms considered, except for the double mutants dm R401C and dm R527P (Fig. 3C and 3D).

To get more insight into Ankrd2 subcellular distribution following $\mathrm{H}_{2} \mathrm{O}_{2}$ stimulation, HEK 293T cells were co-transfected with Ankrd2 and lamin A wild type (LA WT) or double mutants, and treated with $\mathrm{H}_{2} \mathrm{O}_{2}$ as before. Cells were collected after 30 minutes and 3 hours from stimulation, fractionated and Ankrd2 was detected and quantified in nuclear fractions. Results shown in Fig. 3E demonstrated that in Ankrd2-LA WT co-transfected cells, the application of stress immediately induced Ankrd2 to shuttle to the nucleus. However, the presence of Ankrd2 in the nucleus was not enduring, as longer $\mathrm{H}_{2} \mathrm{O}_{2}$ exposure reduced its amount (Fig. 3E). This evidence suggests that upon the application of $\mathrm{H}_{2} \mathrm{O}_{2}$, Ankrd2 crosses 


\section{Cellular Physiology Cell Physiol Biochem 2017;42:169-184 \begin{tabular}{c|l} 
DOI: 10.1159/000477309 & $\begin{array}{l}\text { () } 2017 \text { The Author(s). Published by S. Karger AG, Basel } \\
\text { www.karger.com/cpb }\end{array}$
\end{tabular}}

Angori et al.: Ankrd2 is a Novel Interactor of Lamin A and Prelamin A

Fig. 4. Analysis of Ankrd2 subcellular localization and ROS release upon oxidative stress stimulation in human cultured EDMD2 muscle cells. A) Primary human muscle cultures from healthy (Control) and EDMD2 donors (EDMD2 a and b) (LMNA mutation: c.1517A>C/p.H506P) were cultured and differentiated on coverslips. After 3 weeks, cells were processed for immunofluorescence and stained for Ankrd2 (green) and lamin A/C (red); chromatin was counterstained with DAPI. Bar $10 \mu \mathrm{m}$. The most significant nuclei (indicated by arrowheads) were magnified to highlight Ankrd2 localization. Partial co-localization signals between Ankrd2 and lamin A/C are evidenced by arrows. Represented EDMD2 myotubes highlight differences in nuclear morphology that can be found in the culture. In particular: a) shows little or no dysmorphic nuclei, while b) shows highly dysmorphic nuclei. B) Primary human muscle cultures from the healthy and EDMD2 donors of A) were cultured in triplicates in 96-well plate as described in "Methods". When similar levels of differentiation were

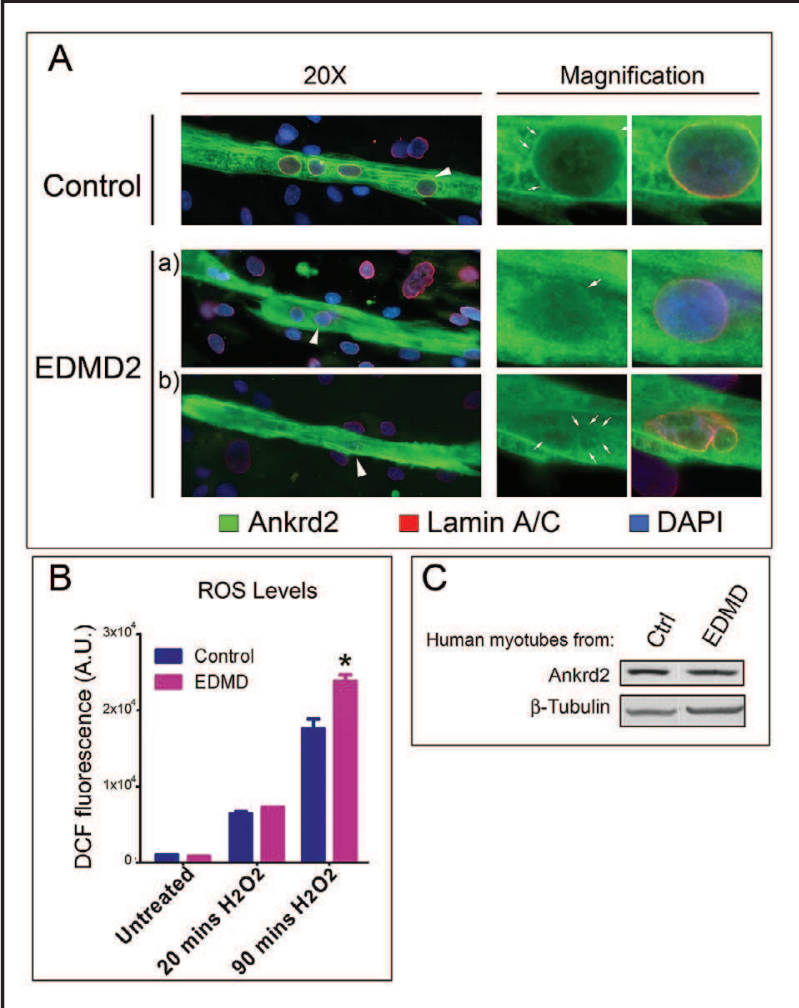
obtained (mature myotubes were defined as those with $\geq 3$ nuclei), cells were incubated with dichlorfluorescein-diacetate (DCF-DA), stimulated with $100 \mu \mathrm{M} \mathrm{H}_{2} \mathrm{O}_{2}$ and ROS levels immediately measured as described. In unstimulated conditions, healthy and EDMD2 myotubes released similar amount of ROS. However, following 90 minutes of $\mathrm{H}_{2} \mathrm{O}_{2}$ exposure, ROS released from EDMD2 myotubes was $30 \%$ greater than those from control samples. Graph represents the mean \pm SD $(n=3),{ }^{*} p<0.05$ vs. control muscle cells treated under the same conditions. C) To demonstrate the levels of Ankrd2 expression, at the end of the experiment control and EDMD2 cultures were lysed in $40 \mu \mathrm{l}$ of SDS-buffer, loaded on a $12 \%$ SDS-PAGE, and immunoblotted with antibodies against Ankrd2. $\beta$-tubulin was used to demonstrate equal loading.

the nuclear lamina, by interacting with lamin A, accumulating in the nucleus for a certain time frame and then cycling back into the cytoplasm shortly after.

This trend was not confirmed by cells in which Ankrd2 was co-expressed with lamin A-EDMD2- lamin A-mutants. Under these experimental conditions in fact, the amount of nuclear Ankrd2 was clearly higher than that observed in control cells (Ankrd2-LA WT cotransfected one) and what is more, persistent $\mathrm{H}_{2} \mathrm{O}_{2}$ stimulation did not reduce Ankrd2 amount in the nucleus, as highlighted in control cells, likely because of the "sticky" interaction with mutated lamin A (Fig. 3D). Of note, in LA dm R527P co-transfectants, upon three hours of treatment, the amount of nuclear Ankrd2 remarkably decreased (Fig. 3E). Albeit substantial, this reduction resulted in a nuclear retention of Ankrd2 that was higher than that observed in LA WT counterpart, leading us to consider also this variation as significative.

\section{Ankrd2 localization in primary muscle cultures from EDMD2-affected human donors}

With the purpose of investigating whether Ankrd2 subcellular localization is impaired also in myotubes from EDMD2-affected patients, human muscle cultures obtained from healthy donors and donors suffering from an EDMD2 form with severe conduction defects, were grown, differentiated and processed for an ex vivo analysis of Ankrd2 localization. Ankrd2 immunostaining revealed that Ankrd2 had a similar cytoplasmic localization both in healthy and in pathological samples. Analysis of Ankrd2 nuclear staining of both samples revealed that Ankrd2 partially co-localized with lamin A/C at the nuclear lamina. However, 


\section{Cellular Physiology Cell Physiol Biochem 2017;42:169-184

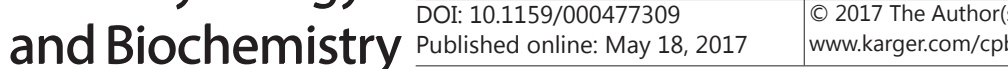

Angori et al.: Ankrd2 is a Novel Interactor of Lamin A and Prelamin A

whereas in healthy conditions Ankrd2 was poorly localized at the nuclear rim of $70 \%$ of total nuclei (Fig. 4A, Control), in nuclei of pathological myotubes Ankrd2 antibody stained a higher percentage of nuclei $(\sim 90 \%)$ in a diffuse fashion (Fig. 4A, EDMD2-a). All these findings agree with the results shown in Fig. 2, on the nuclear recruitment of Ankrd2 in HEK 293T and C2C12 muscle cells overexpressing EDMD2 mutated forms of lamin A or prelamin A. Finally, nuclear dysmorphism was clearly detectable in EDMD2 myotubes (about more than the half of the culture). In these conditions, although the loss of nuclear boundaries was evident (Fig. 4A, EDMD2-b), the partial co-localization of Ankrd2 and lamin $\mathrm{A} / \mathrm{C}$ in proximity of nuclear aberrant structures $\mathrm{A} / \mathrm{C}$ was still clearly detectable (Fig. 4A, EDMD2-b).

Interestingly, confirming published data [22, 35, 36], also muscle fibers from our patient responded to $\mathrm{H}_{2} \mathrm{O}_{2}$ stimulation by increasing the amount of ROS release of about $30 \%$, compared to the control (Fig. 4B). At the end of the assay, the analysis of the cell lysates revealed similar level of Ankrd2 expression (Fig. 4C). The results shown in Fig. 4A and 4B and the fact that Ankrd2 is a stress responsive protein led us to hypothesize that the localization of Ankrd2 in the nuclei of EDMD2 cells might be involved in their altered stress response.

Concomitant expression of Ankrd2 and pathological lamin A forms affect ROS release and cell viability in response to stress stimulation

In dystrophic muscle cells, the dysfunctional nuclear lamina caused by the accumulation of mutated lamin A, leads to an anomalous increase of the amount of cellular ROS, dramatically concurring with the impairment of the pathology [26]. Therefore, we wondered whether the forms examined in this work were able to increase the cellular susceptibility to stress. HEK 293T overexpressing wild-type or EDMD2 lamin A forms were stimulated with $\mathrm{H}_{2} \mathrm{O}_{2}$, and the amount of ROS was quantified by the DCF-DA assay.

Results shown in Fig. 5A demonstrate that following $\mathrm{H}_{2} \mathrm{O}_{2}$ stimulation, LA dm R527P-overexpressing cells released an amount of ROS higher $(\sim 12 \%)$ than the LA WT overexpressing one. Similar findings were obtained with all the EDMD2-mutants tested, although the LA double mutant overexpression was always much more effective than the single counterparts (not shown).

With the aim of demonstrating whether the observed ROS increase might be affected by Ankrd2 accumulation in the nucleus, HEK 293T cells were co-transfected with vectors encoding Ankrd2 and lamin A WT or mutated forms, stressed and assayed for ROS release as before. Surprisingly, co-expression of Ankrd2 and LA dm R527P increased the amount of ROS released by more than 20\% compared to cells expressing LA dm R527P alone (Fig. 5A), more than 35\% compared to cells expressing LA WT alone, and more than 30\% compared to cells expressing Ankrd2 and LA WT. The analysis of the corresponding lysates revealed that all the samples were properly transfected (Fig. 5B).

To investigate whether the simultaneous expression of Ankrd2 and LA dm R527P was also able to affect cell viability in response to stress, HEK 293T cells were transfected as before and subjected to stress at various time points. At the end of every treatment, viable cells were counted by Trypan blue exclusion. Simultaneous expression of Ankrd2 and LA $\mathrm{dm}$ R527P halved cellular viability $\sim 3$ hours before that of cells expressing LA dm R527P alone or Ankrd2 in combination with LA WT (Fig. 5C). Immunochemical analysis of the same samples indicated that cell death had apoptotic features (Fig. 5D).

Taken together, these data demonstrate that the dysfunctional nuclear lamina, together with the nuclear recruitment of Ankrd2, induced by mutated lamina itself, synergistically act to increase cellular susceptibility to stress.

\section{Discussion}

The results presented in this study point to Ankrd2 as a new interactor of lamin A and its precursor prelamin A. In particular, our results reveal that prelamin $\mathrm{A}$ is able to complex with higher amounts of Ankrd2 compared to mature lamin A, suggesting that in 


\section{Cellular Physiology Cell Physiol Biochem 2017;42:169-184

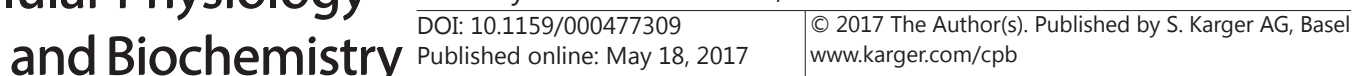

Fig. 5. Analysis of the response to oxidative stress in cells co-expressing Ankrd2 and EDMD2-mutant form of prelamin A. A) HEK 293T cells were transfected with constructs encoding Flag (Fl-) tagged lamin A WT (LA WT) or LA dm R527P, chosen as an EDMD2-mutated prelamin A representative mutant, plus, where indicated, Flag tagged Ankrd2, and loaded with DCFDA. As control of toxicity, untransfected cells (Not Transfected) were subjected to the same test. Cells were next exposed to stress by $\mathrm{H}_{2} \mathrm{O}_{2}$ stimulation (f.c. $450 \mu \mathrm{M}$ ) and the amount of ROS released immediately evaluated as the amount of oxidized DCF (DCFHDA). The graph reports ROS values in untreated conditions ( - ) and after 25 minutes from $\mathrm{H}_{2} \mathrm{O}_{2}$ application from triplicate readings. Data are the mean from three independent experiments (one of which is shown here) \pm SD. Statistically significant differences with respect to the control (LA WT- transfected cells) value were determined by the Student's t-test $(p<0.05)$. Expression of Fl-LA dm R527P increased the amount of ROS by $12 \%$ compared to the control (cells expressing Fl-LA WT alone), whereas co-expression of FlAnkrd2 and Fl-LA dm R527P increased the amount of ROS by more than 35\% compared to the control, and more than $30 \%$ compared to Fl-LA WT and Fl-Ankrd2. B) At the end of the experiment, samples were lysed and subjected to Western blot analysis to detect
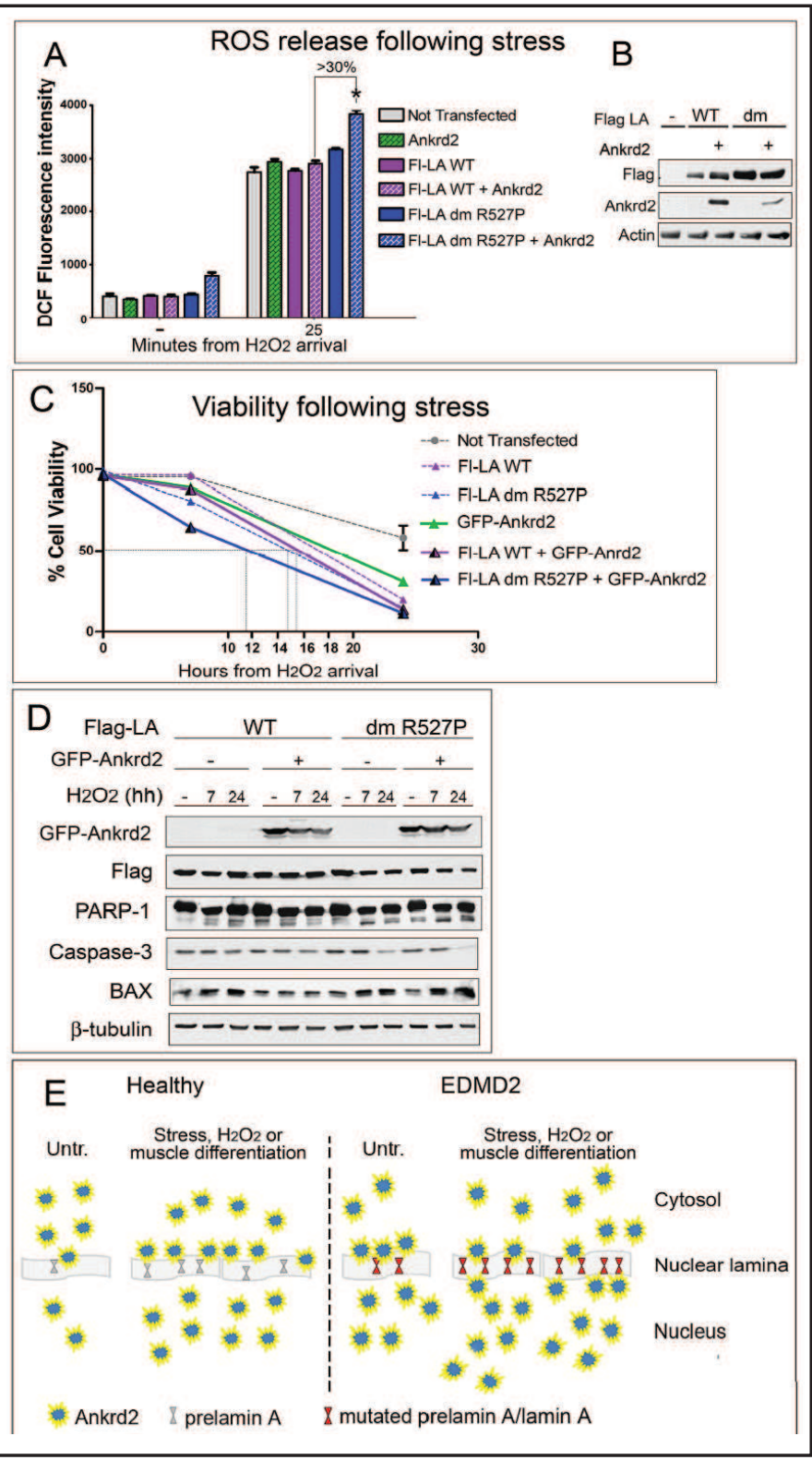
GFP-Ankrd2 and Fl-LA. Equal loading was confirmed by the amount of actin. C) HEK 293T cells plated in p100 were transfected as before. The next day, cells were trypsinized and plated at a density of $0.5 \times 10^{6} /$ well onto a 6-well plate. After 24 hours cells were subjected to oxidative stress by $450 \mu \mathrm{M} \mathrm{H}_{2} \mathrm{O}_{2}$ stimulation. After 7 and 24 hours, cell viability was assessed by the Trypan blue assay. Dotted lines indicate the time at which cells halve their number. Graphs are presented with the percent cell viability \pm SD for the respective independent experiments $(n=3)$. D) To verify apoptotic cell death, HEK 293T cells of C) were collected at the end of each treatments and lysed. Total lysates were immunoblotted with antibodies directed against PARP-1, caspase- 3 and BAX. Equal levels of transfection of GFP-Ankrd 2 and Flag lamins are shown. The amount of $\beta$-tubulin detected confirmed equal loading. E) Schematic interpretation of the results presented in this study: in healthy donors, in untreated cells (Untr.), the nuclear lamina is principally made of mature lamin A. In these conditions, Ankrd2 poorly binds to lamin A, and is weakly found in the nuclei of cells. Ankrd2 shuttling to the nucleus, which is observed upon mechanical, or oxidative $\left(\mathrm{H}_{2} \mathrm{O}_{2}\right)$ stress application, or muscle differentiation, probably occurs also as a consequence of prelamin A accumulation at the nuclear lamina (observed under the same conditions by other Authors, see text), which in turn interacts with Ankrd2 resulting in Ankrd2 nuclear recruitment. In pathological conditions (EDMD2), nuclear lamina mainly consist of mutated prelamin A and lamin A, which are able to recruit Ankrd2 even in the absence of stimulation. 


\section{Cellular Physiology Cell Physiol Biochem 2017;42:169-184

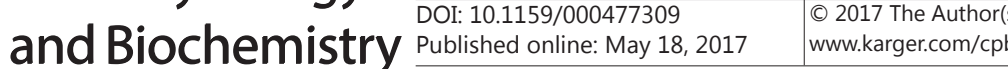

Angori et al.: Ankrd2 is a Novel Interactor of Lamin A and Prelamin A

in vivo conditions, this intermediate might form a stronger interaction with Ankrd2. We are currently involved in interaction studies to assess the nature of Ankrd2 binding to lamin A or farnesylated prelamin $\mathrm{A}$, whether it is direct or mediated by other molecules.

Ankrd2 is a "cytonuclear" protein and is thus expressed both in the cytoplasm and in the nucleus of the cells. In an attempt to assess whether Ankrd2 subcellular localization might be affected by its interaction with prelamin $\mathrm{A}$, we also demonstrated that when overexpressed with this precursor, and not with mature lamin A, Ankrd2 partially redistributes to the nucleus (Fig. 1 and S2, see supplementary material). Interestingly, we proved that the interaction between Ankrd2 and farnesylated prelamin A, or mature lamin A, is not static but positively modulated by oxidative stress application which, as already reported, induces Ankrd2 translocation into the nucleus. In particular, in the last years, farnesylated prelamin A has been indicated as more than a simple precursor fastly processed to give lamin A. Recent studies have in fact demonstrated the centrality of the role played by prelamin A in some cellular events, such as myogenesis, that requires the accumulation of prelamin A to coordinate proper nuclear positioning in muscle cells $[28,30]$, or the oxidative stress response, in which elevated levels of prelamin A by inducing DNA damage, lead to premature cellular senescence $[37,38]$. Our evidence thus suggest the existence of a multimeric complex consisting of Ankrd2, mature lamin A and prelamin A, the composition of which is ruled by cellular conditions. In non-pathological conditions, at the steady state, this complex features a huge amount of mature lamin A which weakly binds to Ankrd2, thus causing Ankrd2 to be poorly accumulated at the nuclear level. Following the application of stress, or myogenic stimuli arrival, the multimeric complex changes its composition, accumulating prelamin A that in turn acts by pulling in Ankrd2. At this point, after being brought closer to the nucleus, through mechanisms still to be elucidated, Ankrd2 translocates into the nucleus.

In an attempt to assess Ankrd2 involvement in the pathophysiology of EDMD2, a muscle disorder associated with mutations in the LMNA gene, Ankrd2 was assayed for its ability to bind some mutated forms of lamin A causative of this pathology. Our results prove that compared to wild type counterparts, EDMD2-mutated forms of lamin A or prelamin A form a higher interaction with Ankrd2. Furthermore, opposite to wild-type forms, the "pathological" interactions are not increased by stress stimulation (Fig. 2A and 2B). Nevertheless, in vivo analysis revealed that all the EDMD2-forms of lamin A tested are also able to affect the regular localization of Ankrd2, inducing a partial recruitment of Ankrd2 to the nucleus (Fig. 2C, 2D and $3 \mathrm{E}$ ). It is interesting to note, that the mutant forms of lamins appeared to cause two distinct nuclear phenotypes for Ankrd2, that is a diffuse nuclear staining and punctate foci. Although at the moment we are unable to assess what are the downstream consequences of these Ankrd2 nuclear patterns, we exclude that they might be related to the relative levels of exogenous proteins, but rather to the severity of the lamin A mutation.

According to the latest evidence, it was reasonable to speculate that also in pathological muscle cells, Ankrd2 is sequestered and mislocated in the nucleus by mutated lamin A. Confirming this hypothesis, our evidence proves that in cultured myotubes obtained from an EDMD2 affected donor, and opposite to unaffected myotubes, Ankrd2 is typically found in a high percentage of nuclei (Fig. 4A).

Going back to our multimeric complex model, in pathological conditions, the complex Ankrd2-lamin A-prelamin A is enriched in mutated lamin A or prelamin A which, as demonstrated, have a high affinity for Ankrd2, and cause a portion of total Ankrd2 to be constitutively localized at the nuclear level, also in the absence of stimuli (a schematic cartoon is depicted in Fig. 5E).

Very recently, it has been reported that, besides the S-Ankrd2 isoform studied in this paper, nuclei of primary differentiated myotubes also feature a longer Ankrd2 isoform, that is M-Ankrd2, which is identical to the S- one except for a unique region of 27 amino acids at its $\mathrm{N}$-terminus [3]. As our findings suggest, the accumulation of Ankrd2 shown in affected myotubes might be due to the stronger interaction formed between S-Ankrd2 and the EDMD2-lamin A. Future experiments are planned to investigate whether and how lamin A also interacts with the M-Ankrd2 isoform. 


\section{Cellular Physiology Cell Physiol Biochem 2017;42:169-184 \begin{tabular}{c|l} 
DOI: 10.1159/000477309 & $\begin{array}{l}\text { @ } 2017 \text { The Author(s). Published by S. Karger AG, Basel } \\
\text { www.karger.com/cpb }\end{array}$ \\
and Biochemistry Publisned onIne: 1vay 18, 2017 &
\end{tabular} \\ Angori et al.: Ankrd2 is a Novel Interactor of Lamin A and Prelamin A}

In dystrophic muscle cells, the accumulation of mutated lamin A leads to an anomalous increase of the amount of cellular ROS in response to mechanical [36] or oxidative stress $[27,39-41]$, concurring to the impairment of the pathology [26]. This evidence has also been confirmed in our patient (ROS assay, Fig. 4B). With the purpose of investigating whether the nuclear recruitment of Ankrd2 concomitant with EDMD2-lamin A overexpression might affect the cellular response to oxidative stress, our results prove that the combined expression of Ankrd2 and EDMD2 - lamin A is toxic, as it resulted in an increase of cellular sensibility to stress (Fig. 5A) associated to a premature apoptotic cell death (Fig. 5C and 5D). Evidence is necessary to verify the exact connection between Ankrd2 nuclear accumulation and increased ROS release in response to stress. Supported by our data, we therefore suggest that the nuclear accumulation of Ankrd2 observed in human EDMD2 muscle cells might contribute to generate the abnormal response to oxidative stress observed in Fig. 4B.

Intriguingly, recent published studies have demonstrated that muscle fibers of Ankrd2KO (knock out) mice are less stiff than wild-type fibers, probably due to the loss of sarcomeric Ankrd2 resulting in a general disorganization within the sarcomere [42]. Similarly, recent findings demonstrate that EDMD2 forms of lamin A are responsible for the reduction of nuclear stiffness of muscle cells rendering fibers more sensitive to mechanical stimuli [43]. In this context, it should be interesting to evaluate if and how the nuclear accumulation of Ankrd2 contributes to the reduction in stiffness of EDMD2 fibers: maybe by subtracting Ankrd2 molecules from the sarcomeric fraction, or maybe by affecting the expression of genes involved in the formation of functional sarcomeres, or both. To us, this is an interesting issue that undoubtedly warrants further investigations.

All in all, by suggesting a molecular mechanism ruling the anomalous nuclear accumulation of Ankrd2 during the expression of some EDMD2-associated forms of lamin A, our findings for the first time introduce Ankrd2 as a plausible mediator of the mutated functions of lamin A, laying the foundations for future investigations related to the pathophysiology of EDMD2.

\section{Acknowledgments}

This work was supported by grants from: "5 per mille 2013 e 2014" - Rizzoli Orthopaedic Institute, AIDMED (Associazione Italiana Distrofia Muscolare di Emery Dreifuss), A.I.Pro.Sa.B. (Associazione Italiana Progeria Sammy Basso) and Fondazione Del Monte Grant 20.07.2015.

We thank all the Dr. W. Blalock's lab at the IGM-CNR-IOR, Bologna, for critical suggestions, and A. Valmori IGM-CNR Bologna and D. Zini and S. Grasso IOR, for technical assistance. The authors also thank all the members of the Italian Network for Laminopathies (www.igm.cnr. it/1/laminopatie/).

\section{Disclosure Statement}

No competing financial interests exist.

\section{References}

1 Moriyama M, Tsukamoto Y, Fujiwara M, Kondo G, Nakada C, Baba T, Ishiguro N, Miyazaki A, Nakamura K, Hori N, Sato K, Shomori K, Takeuchi K, Satoh H, Mori S, Ito H: Identification of a novel human ankyrinrepeated protein homologous to CARP. Biochem Biophys Res Commun 2001;285:715-723.

- Ishiguro N, Baba T, Ishida T, Takeuchi K, Osaki M, Araki N, Okada E, Takahashi S, Saito M, Watanabe M, Nakada C, Tsukamoto Y, Sato K, Ito K, Fukayama M, Mori S, Ito H, Moriyama M: Carp, a cardiac ankyrinrepeated protein, and its new homologue, Arpp, are differentially expressed in heart, skeletal muscle, and rhabdomyosarcomas. Am J Pathol 2002;160:1767-1778. 


\section{Cellular Physiology Cell Physiol Biochem 2017;42:169-184 \begin{tabular}{l|l} 
and Biochemistry Publisned onlIne: IVlay 18, 2017 & $\begin{array}{l}\text { () 2017 The Author(s). Published by S. Karger AG, Basel } \\
\text { www.karger.com/cpb }\end{array}$
\end{tabular}}

Angori et al.: Ankrd2 is a Novel Interactor of Lamin A and Prelamin A

3 Jasnic-Savovic J, Krause S, Savic S, Kojic A, Kovcic V, Boskovic S, Nestorovic A, Rakicevic L, Schreiber-Katz O, Vogel JG, Schoser BG, Walter MC, Valle G, Radojkovic D, Faulkner G, Kojic S: Differential expression and localization of Ankrd2 isoforms in human skeletal and cardiac muscles. Histochem Cell Biol 2016

4 Bean C, Salamon M, Raffaello A, Campanaro S, Pallavicini A, Lanfranchi G: The Ankrd2, Cdkn1c and calcyclin genes are under the control of MyoD during myogenic differentiation. J Mol Biol 2005;349:349-366.

5 Bean C, Facchinello N, Faulkner G, Lanfranchi G: The effects of Ankrd2 alteration indicate its involvement in cell cycle regulation during muscle differentiation. Biochim Biophys Acta 2008;1783:1023-1035.

6 Kojic S, Medeot E, Guccione E, Krmac H, Zara I, Martinelli V, Valle G, Faulkner G: The Ankrd2 protein, a link between the sarcomere and the nucleus in skeletal muscle. J Mol Biol 2004;339:313-325.

-7 Belgrano A, Rakicevic L, Mittempergher L, Campanaro S, Martinelli VC, Mouly V, Valle G, Kojic S, Faulkner G: Multi-tasking role of the mechanosensing protein Ankrd2 in the signaling network of striated muscle. PLoS One 2011;6:e25519.

-8 Mohamed JS, Lopez MA, Cox GA, Boriek AM: Ankyrin repeat domain protein 2 and inhibitor of DNA binding 3 cooperatively inhibit myoblast differentiation by physical interaction. J Biol Chem 2013;288:2456024568.

-9 Cenni V, Bavelloni A, Beretti F, Tagliavini F, Manzoli L, Lattanzi G, Maraldi NM, Cocco L, Marmiroli S: Ankrd2/ARPP is a novel Akt2 specific substrate and regulates myogenic differentiation upon cellular exposure to H(2)O(2). Mol Biol Cell 2011;22:2946-2956.

10 Miller MK, Bang ML, Witt CC, Labeit D, Trombitas C, Watanabe K, Granzier H, McElhinny AS, Gregorio CC, Labeit S: The muscle ankyrin repeat proteins: CARP, ankrd2/Arpp and DARP as a family of titin filamentbased stress response molecules. J Mol Biol 2003;333:951-964.

11 Martinelli VC, Kyle WB, Kojic S, Vitulo N, Li Z, Belgrano A, Maiuri P, Banks L, Vatta M, Valle G, Faulkner G: ZASP interacts with the mechanosensing protein Ankrd2 and p53 in the signalling network of striated muscle. PLoS One 2014;9:e92259.

-12 Kemp TJ, Sadusky TJ, Saltisi F, Carey N, Moss J, Yang SY, Sassoon DA, Goldspink G, Coulton GR: Identification of Ankrd2, a novel skeletal muscle gene coding for a stretch-responsive ankyrin-repeat protein. Genomics 2000;66:229-241.

13 Lehti TM, Silvennoinen M, Kivela R, Kainulainen H, Komulainen J: Effects of streptozotocin-induced diabetes and physical training on gene expression of titin-based stretch-sensing complexes in mouse striated muscle. Am J Physiol Endocrinol Metab 2007;292:E533-542.

14 Worman HJ: Nuclear lamins and laminopathies. J Pathol 2012;226:316-325.

-15 Shumaker DK, Dechat T, Kohlmaier A, Adam SA, Bozovsky MR, Erdos MR, Eriksson M, Goldman AE, Khuon S, Collins FS, Jenuwein T, Goldman RD: Mutant nuclear lamin A leads to progressive alterations of epigenetic control in premature aging. Proc Natl Acad Sci U S A 2006;103:8703-8708.

-16 Cenni V, Capanni C, Mattioli E, Columbaro M, Wehnert M, Ortolani M, Fini M, Novelli G, Bertacchini J, Maraldi NM, Marmiroli S, D'Apice MR, Prencipe S, Squarzoni S, Lattanzi G: Rapamycin treatment of Mandibuloacral dysplasia cells rescues localization of chromatin-associated proteins and cell cycle dynamics. Aging (Albany NY) 2014;6:755-770.

17 Krishnan V, Chow MZ, Wang Z, Zhang L, Liu B, Liu X, Zhou Z: Histone H4 lysine 16 hypoacetylation is associated with defective DNA repair and premature senescence in Zmpste24-deficient mice. Proc Natl Acad Sci U S A 2011;108:12325-12330.

-18 Mattout-Drubezki A, Gruenbaum Y: Dynamic interactions of nuclear lamina proteins with chromatin and transcriptional machinery. Cell Mol Life Sci 2003;60:2053-2063.

19 Mejat A, Misteli T: LINC complexes in health and disease. Nucleus 2010;1:40-52.

20 Warren DT, Zhang Q, Weissberg PL, Shanahan CM: Nesprins: intracellular scaffolds that maintain cell architecture and coordinate cell function? Expert Rev Mol Med 2005;7:1-15.

-21 Azibani F, Muchir A, Vignier N, Bonne G, Bertrand AT: Striated muscle laminopathies. Semin Cell Dev Biol 2014;29:107-115.

22 Emery AE: Emery-Dreifuss muscular dystrophy - a 40 year retrospective. Neuromuscul Disord 2000;10:228-232.

23 Bonne G, Di Barletta MR, Varnous S, Becane HM, Hammouda EH, Merlini L, Muntoni F, Greenberg CR, Gary F, Urtizberea JA, Duboc D, Fardeau M, Toniolo D, Schwartz K: Mutations in the gene encoding lamin A/C cause autosomal dominant Emery-Dreifuss muscular dystrophy. Nat Genet 1999;21:285-288. 


\section{Cellular Physiology Cell Physiol Biochem 2017;42:169-184 \begin{tabular}{ll|l} 
DOI: 10.1159/000477309 & $\begin{array}{l}\text { ( ) 2017 The Author(s). Published by S. Karger AG, Basel } \\
\text { www.karger.com/cpb }\end{array}$
\end{tabular}}

Angori et al.: Ankrd2 is a Novel Interactor of Lamin A and Prelamin A

24 Bonne G, Leturcq F, Ben Yaou R: Emery-Dreifuss Muscular Dystrophy; in Pagon RA, Adam MP, Ardinger HH, Wallace SE, Amemiya A, Bean LJH, Bird TD, Fong CT, Mefford HC, Smith RJH, Stephens K (eds): GeneReviews(R). Seattle (WA), 1993

25 Dahl KN, Ribeiro AJ, Lammerding J: Nuclear shape, mechanics, and mechanotransduction. Circ Res 2008;102:1307-1318.

26 Tidball JG, Wehling-Henricks M: The role of free radicals in the pathophysiology of muscular dystrophy. J Appl Physiol (1985) 2007;102:1677-1686.

-27 Sieprath T, Darwiche R, De Vos WH: Lamins as mediators of oxidative stress. Biochem Biophys Res Commun 2012;421:635-639.

-28 Capanni C, Del Coco R, Squarzoni S, Columbaro M, Mattioli E, Camozzi D, Rocchi A, Scotlandi K, Maraldi N, Foisner R, Lattanzi G: Prelamin A is involved in early steps of muscle differentiation. Exp Cell Res 2008;314:3628-3637.

29 Sinensky M, Fantle K, Trujillo M, McLain T, Kupfer A, Dalton M: The processing pathway of prelamin A. J Cell Sci 1994;107:61-67.

30 Mattioli E, Columbaro M, Capanni C, Maraldi NM, Cenni V, Scotlandi K, Marino MT, Merlini L, Squarzoni S, Lattanzi G: Prelamin A-mediated recruitment of SUN1 to the nuclear envelope directs nuclear positioning in human muscle. Cell Death Differ 2011;18:1305-1315.

-31 Cenni V, Sabatelli P, Mattioli E, Marmiroli S, Capanni C, Ognibene A, Squarzoni S, Maraldi NM, Bonne G, Columbaro M, Merlini L, Lattanzi G: Lamin A N-terminal phosphorylation is associated with myoblast activation: impairment in Emery-Dreifuss muscular dystrophy. J Med Genet 2005;42:214-220.

32 Capanni C, Mattioli E, Columbaro M, Lucarelli E, Parnaik VK, Novelli G, Wehnert M, Cenni V, Maraldi NM, Squarzoni S, Lattanzi G: Altered pre-lamin A processing is a common mechanism leading to lipodystrophy. Hum Mol Genet 2005;14:1489-1502.

-33 Pan Y, Garg A, Agarwal AK: Mislocalization of prelamin A Tyr646Phe mutant to the nuclear pore complex in human embryonic kidney 293 cells. Biochem Biophys Res Commun 2007;355:78-84.

34 Dittmer TA, Misteli T: The lamin protein family. Genome Biol 2011;12:222.

35 Pekovic V, Gibbs-Seymour I, Markiewicz E, Alzoghaibi F, Benham AM, Edwards R, Wenhert M, von Zglinicki T, Hutchison CJ: Conserved cysteine residues in the mammalian lamin A tail are essential for cellular responses to ROS generation. Aging Cell 2011;10:1067-1079.

-36 Muchir A, Worman HJ: Emery-Dreifuss muscular dystrophy. Curr Neurol Neurosci Rep 2007;7:78-83.

-37 Ragnauth CD, Warren DT, Liu Y, McNair R, Tajsic T, Figg N, Shroff R, Skepper J, Shanahan CM: Prelamin A acts to accelerate smooth muscle cell senescence and is a novel biomarker of human vascular aging. Circulation 2010;121:2200-2210.

-38 Liu Y, Drozdov I, Shroff R, Beltran LE, Shanahan CM: Prelamin A accelerates vascular calcification via activation of the DNA damage response and senescence-associated secretory phenotype in vascular smooth muscle cells. Circ Res 2013;112:e99-109.

-39 Richards SA, Muter J, Ritchie P, Lattanzi G, Hutchison CJ: The accumulation of un-repairable DNA damage in laminopathy progeria fibroblasts is caused by ROS generation and is prevented by treatment with $\mathrm{N}$-acetyl cysteine. Hum Mol Genet 2011;20:3997-4004.

-40 Verstraeten VL, Caputo S, van Steensel MA, Duband-Goulet I, Zinn-Justin S, Kamps M, Kuijpers HJ, Ostlund C, Worman HJ, Briede JJ, Le Dour C, Marcelis CL, van Geel M, Steijlen PM, van den Wijngaard A, Ramaekers FC, Broers JL: The R439C mutation in LMNA causes lamin oligomerization and susceptibility to oxidative stress. J Cell Mol Med 2009;13:959-971.

-41 Caron M, Auclair M, Donadille B, Bereziat V, Guerci B, Laville M, Narbonne H, Bodemer C, Lascols O, Capeau J, Vigouroux C: Human lipodystrophies linked to mutations in A-type lamins and to HIV protease inhibitor therapy are both associated with prelamin A accumulation, oxidative stress and premature cellular senescence. Cell Death Differ 2007;14:1759-1767.

-42 Barash IA, Bang ML, Mathew L, Greaser ML, Chen J, Lieber RL: Structural and regulatory roles of muscle ankyrin repeat protein family in skeletal muscle. Am J Physiol Cell Physiol 2007;293:C218-227.

43 Davidson PM, Lammerding J: Broken nuclei--lamins, nuclear mechanics, and disease. Trends Cell Biol 2014;24:247-256. 